\title{
Impact of Fertilizer on Maize Yield Growth in Ethiopia: The Implementation of the Difference-in-Differences Matching Estimator
}

\author{
Fitsum Daniel \\ Ethiopian Institute of Agricultural Research, Addis Ababa, Ethiopia
}

\begin{abstract}
This study examines the national level impact of adoption of fertilizer (organic, inorganic or both) on maize yield growth in Ethiopia. In so doing, a balanced panel data set covering two time periods was used and propensity score matching in combination with a difference-in-differences estimator was employed to better match control and project units on preprogram observable characteristics and to control for certain types of unobserved variables which can be assumed to remain fixed over a shorter time series. It is found that adoption of fertilizer had positive and significant impact on maize yield growth at national level. Therefore, this study recommends to widely scaleup fertilizer to all maize producing farm households, and this should be accompanied by increasing availability of affordable fertilizer for the smallholder farmers to enhance their livelihood.
\end{abstract}

Keywords: Impact, Maize, Fertilizer, Ethiopia

DOI: $10.7176 / \mathrm{JNSR} / 11-21-05$

Publication date: November $30^{\text {th }} 2020$

\section{Introduction}

Agriculture in Ethiopia is a basis for the entire socioeconomic structure of the country and has a major influence on all other economic sectors and development processes (Elias et al., 2013; GebreEyesus, 2015). Despite the marginal decline in its share of GDP in recent years, it is still the single largest sector in terms of its contribution to GDP as agricultural GDP constitutes $41 \%$ of total country's GDP (CSA, 2014/15).

As to Gebru 2006 citing CSA 2003, out of the total production of agriculture, about $70 \%$ comes from crop production. According to Abegaz 2011, cereal crops constitute the largest share of farming household's production and consumption activities. Accordingly citing Alemayehu et al., 2009, only five major cereals (barley, maize, sorghum, teff and wheat) account for about $70 \%$ of area cultivated and $65 \%$ of output produced. Fertilizer use is also concentrated on cereals followed by pulses and oilseeds respectively according to Endale 2011 citing CSA 1995/96-2007/08. Moreover, Abegaz 2011 citing the Household Income, Consumption and Expenditure Survey of CSA indicated that the five major cereal crops account for $46 \%$ of household's total consumption. Abate et al. 2015 indicated that maize, teff (Eragrostis tef), sorghum, wheat, and barley among cereals and enset (Ensete ventricosum) ("false banana") among "roots and tubers" provide the main calorie requirements in the Ethiopian diet. Therefore, a closer look at what is happening in cereal production has an important welfare and policy implication in Ethiopia (Abegaz, 2011).

According to Kelemu 2017 citing FAO 2014, maize is the first most important food in the country in terms of caloric intake. According to Jaleta et al. 2015 citing CSA 2014b, on average, 76\% of maize produced is consumed at home and no other cereal crop produced reaches to this level in terms of retention for home consumption. At present, as a sub-Saharan country, Ethiopia has the fifth largest area devoted to maize but is second, only to South Africa, in yield and third, after South Africa and Nigeria, in production (Abate et al. 2015). In Ethiopia, maize ranks first in volume of production and second in total allocation to production area. Maize is the second most widely cultivated crop in Ethiopia and is grown under diverse agro-ecologies and socioeconomic conditions typically under rain-fed production (Abate et al. 2015). It is adapted to and grown in diverse agroecologies starting from mid-lowlands to highlands of the country except in both extreme lowlands and highlands (Jaleta et al., 2015). Moreover, according to Abate et al. 2015 citing CSA, 2011-13 data, more than 9 million households, more than for any other crop, grow maize in Ethiopia. Accordingly, the annual rate of growth for the number of households cultivating maize grew at $3.5 \%$ each year between 2004 and 2013, compared to $3.0 \%$ for sorghum, $3.1 \%$ for teff, $2.1 \%$ for wheat, and $1.8 \%$ for barley. Largely because of the increasing demand driven by population growth and competitiveness of the crop, maize area in Ethiopia doubled during the past two decades from 1 to 2 million hectares and the growth in the proportion of maize area was higher than all other major cereals over the last three decades (Abate et al., 2015 citing Rosegrant et al., 2001).

The Ethiopian agricultural sector, as to Gebru 2006 citing EEA 2004, is dominated by small-scale farmers cultivating about $96 \%$ of the total area under crop, producing more than $90 \%$ of total agricultural output and $97 \%$ of food crops. With these statistics, one can easily infer to what extent the small-scale farmers are the key element in strengthening the effort towards agricultural growth and consequently to the overall economic growth (GebreSelassie \& Bekele). 
With respect to all these facts, it is not questionable that accelerated and sustained growth in the country's agriculture in general and in the crop sub-sector in particular with special emphasis to the small-scale farmers will greatly help to achieve the various goals of the country (Gebru, 2006; MoFED, 2003; Gebre-Selassie \& Bekele).

Moreover, food needs as well as the industrial demand for agricultural products increase due to population growth (Bor and Bayaner, 2009). All these needs, according to them, require an increase in the agricultural production. The growth in agricultural production in sub-Saharan Africa in the past was achieved by expanding the amount of land cultivated (Gebru, 2006). In relation with this, it is well known that in our country there are regions where there are large populations but limited land and vice versa (MoFED, 2003). Accordingly, most of the lands available for settlement are found in the lowlands that lack basic infrastructural facilities and pose serious health hazards. With little suitable land available for expansion of crop cultivation, especially in the highlands, future cereal production growth will need to come from increasing land productivity mainly through the supply, duplication and diffusion of continuously improving technology and information (Ayele et al. 2006 citing Reardon et al 1996; Taffesse et al. 2012; Elias et al. 2013; Matsumoto and Yamano, 2010).

Cognizant of these as well as the fact that productivity is the major component of growth and a fundamental requisite in many form of planning irrespective of the stage of development and economic and social system as to Gebru 2006 citing Cheema 1978, maize has received the highest research attention than any other crop in Ethiopia. As a strategic food security crop, since 1970s, international and national research centers exerted collaborative efforts in improving the genetic potential of maize and its adaptability to different agro-ecologies in the country (Jaleta et al., 2015). Accordingly citing MoA 2012, about 60 improved maize varieties have been released or registered in the country since the 1970s through this integrated effort. According to Gebru 2006 citing CSA 2015b, a closer look at the proportion of the area covered by improved varieties of different crops showed that maize took the first rank (46.4\%) among cereals. Given the emphasis of increasing crop production through higher fertilizer use, import of chemical fertilizer augmented from 246,722 MT in 1995 to 375,717 MT in 2006 despite the removal of fertilizer subsidies since 1997/98 according to Endale 2011 citing MOARD 2007/08.

Maize inputs in Ethiopia include mainly improved seed and fertilizers. The use of pesticides (including fungicides, herbicides and insecticides) is insignificant and available data are sparse (Abate et al., 2015). However, according to Jaleta et al. 2015 citing Feleke and Zegeye 2006, Tura et al. 2010 as well as Kassa et al. 2013, the level of improved maize variety adoption by smallholder farmers is still low although a large number of maize varieties have been released. In this regard, Abate et al. 2015 using an unpublished data from MoA mentioned that the share of total modern varieties used in Oromia region during 2010-12 was 49\% of the total; Amhara and South Nations Nationalities and People regions accounted for 33 and 18\%, respectively, with Ben Shangul-Gumuz and Tigray regions both receiving less than 1\% each. They also estimated based on CSA data for 2004 to 2013 that about $23 \%$ of the total mineral fertilizer in Ethiopia is applied to maize. Accordingly, an average of $69 \%$ of all maize grown in 2013 in Ethiopia received some amount of mineral fertilizer application, compared to $56 \%$ in 2004.

Even though crop productivity and production remained low and variable in the 90s for the most part, there have been clear signs of change over the past decade (Abate et al., 2015). Accordingly, national maize yields have doubled from about $1.50 \mathrm{MT} /$ ha during the early 1990s to $3.23 \mathrm{MT} / \mathrm{ha}$ in 2013 . On average, maize area and productivity increased by 4.0 and $6.3 \%$ per annum, respectively, during the 10 years between 2004 and 2013. Similarly, the annual rate of growth for production during the same period was $10.5 \%$ and it is interesting to see that the increases in maize production in Ethiopia resulted more from increases in productivity rather than area expansion (Abate et al., 2015).

As to Tsusaka and Otsuka 2013 citing FAO 2011, although the production of staple food has been increasing in sub-Saharan Africa, the rate of increase has not been high enough to outstrip its high population growth rate as a result of which per-capita agricultural production in the region has declined by about $10 \%$ since 1960 . These all obviously calls for a further and a better growth in agricultural productivity as well as quality with minimum adverse impact on the environment.

With increased production driving market prices down, maize became more affordable (e.g., relative to other staples such as teff and wheat) to rural and urban consumers (Abate et al., 2015). They added that it is now increasingly used both separately as well as in mixed flour with other more expensive cereals in traditional Ethiopian diets. Maize for industrial use has also supported growing demand according to them. Accordingly, though very little maize is currently used as feed, this too is changing in order to support a rapidly growing urbanization and poultry industry. Moreover, if production can be significantly expanded, the potential for maize export to all the neighboring countries including Kenya is very high although the national demand is expected to continue to grow in the coming years (Abate et al., 2015).

Holistic and appropriate evaluation of the efforts and corresponding results as well as reasons/strengths and weaknesses/ of the past few decades in general and of the past recent years in particular is necessary in order to create a more fertile ground for the fast achievement of the aforementioned goal. In this regard, the role of historical data collected by different agencies like CSA as well as of different socio-economic studies carried out to provide 
vital policy and related recommendations is indispensable. Studies that assess the contribution of improved crop management practices information and technologies like improved crop varieties for the productivity growth of such important and widely cultivated cereals like maize in Ethiopia in the past recent years are among studies that can be cited in relation to this. However, studies carried out in the country on this issue are not only few but also restricted to piece meal or location specific approach. Besides, most studies were biased towards those locations that had high/better suitability and/or preference for the production of the specific crop considered. Thus, a nationally or regionally representative data could not be collected for the studies and the conclusions drawn so far would have low probability of influencing national and regional policies. Thus, the objective of this study is to identify the national impact of adoption of fertilizer (organic, inorganic or both) on maize yield growth in Ethiopia.

\section{Materials and Methods}

\subsection{Analytical Framework for Evaluation}

The correct evaluation of the impact of a treatment like adoption of a technology will require identifying the "average treatment effect on the treated" defined as the difference in the outcome variables between the treated objects like farmers and their counterfactual. A counterfactual is defined as "knowledge of what would have happened to those same people if they simultaneously had not received treatment" (Olmos A., 2015 citing Shadish et al., 2002). In this context, as to González et al. 2009, if $Y$ represents the outcome variable and if $D$ is a dummy variable that takes the value of 1 if the individual was treated and 0 otherwise, the "average treatment effect on the treated" will be given by:

$$
\text { (1) } T_{A T T}=E[Y(1) / D=1]-E[Y(0) / D=1]
$$

However, accordingly, given that the counterfactual $(\mathrm{E}[\mathrm{Y}(0) / \mathrm{D}=1])$ is not observed, a proper substitute has to be chosen to estimate $T_{A T T}$. Using the mean outcome of non-beneficiaries-which is more likely observed in most of the cases-do not solve the problem given that there is a possibility that the variables that determine the treatment decision also affect the outcome variables. In this case, the outcome of treated and non-treated individuals might differ leading to selection bias (González et al., 2009). It is usually the case that project beneficiaries have been selected in some way, including self-selection (White et al.). This selection process means that, accordingly, beneficiaries are not a random sample of the population, so that the comparison group should also not be a random sample of the population as a whole, but rather drawn from a population with the same characteristics as those chosen for the intervention.

Propensity score matching (PSM) is an excellent first step toward ensuring that the treatment and comparison groups are comparable - at least on observable covariates (Crown W.H.). According to Olmos A. 2015, propensity scores are defined as the conditional probability of assigning a unit to a particular treatment condition (i.e., likelihood of receiving treatment), given a set of observed covariates. Matching essentially uses statistical techniques to construct an artificial comparison group by identifying for every possible observation under treatment a non-treatment observation (or set of non-treatment observations) that has the most similar characteristics possible (Gertler et al., 2011). The validity of propensity score methods, however, rely on being able to control for the variables that affect treatment selection (assumption of strong ignorability) (Crown W.H.). That is, according to him, the methods assume that any missing variables are uncorrelated with both treatment and outcomes and can be safely ignored. But it is often argued that un-observables play a role, and if these unobservables are correlated with project outcomes then obtaining unbiased estimates of project impact becomes more problematic (White et al.).

Methods based on instrumental variables (IV) or exclusion restrictions represent an alternative econometric strategy for dealing with selection on un-observables (Smith J., 2004). An instrument, or exclusion restriction, according to him, is a variable that affects participation in the treatment but does not affect outcomes other than through its effect on treatment participation (conditional on the other variables included in the outcome equation). The "exclusion restriction" usage arises from the fact that such variables can be excluded from the outcome equation but included in the treatment equation. Unlike longitudinal methods, IV methods require only crosssectional data, and they can potentially deal with selection on un-observables that vary over time (Smith J., 2004).

Unfortunately, implementation of instrumental variables techniques is challenging because, in practice, it is very difficult to identify good instruments, and use of instrumental variables, as a result, may often do more harm than good (Crown W.H.). As a result of the difficulty of finding strong instruments, economists have focused a great deal of attention on the development of non-parametric methods that, with some strong assumptions, can control for certain types of unobserved variables (Crown W.H.). In situations where pre- and post- measurements are available for treatment and comparison group cohorts, accordingly, differences in differences methods provide a non-parametric approach to control for unobserved variables correlated with both treatment and outcomesunder the strong assumption that these unobserved variables are fixed over time (Crown W.H.). The "differencein-differences" estimator compares the before-after change of treated units with the before-after change of untreated units (Smith J., 2004). In so doing, according to him, any common trends, which will show up in the outcomes of the untreated units as well as the treated units, get differenced out. Provided that rich data on control 
and treatment areas exist, propensity score matching (PSM) can be combined with differences in differences (DD) methods to better match control and project units on preprogram characteristics (Khandker et al., 2010).

Even though DD is unbiased only if the potential source of selection bias is additive and time invariant, one can conceive of several cases where unobserved characteristics of a population may indeed change over timestemming, for example, from changes in preferences or norms over a longer time series (Khandker et al., 2010).

\subsection{Data and Variables}

The study used a balanced panel data of maize producers obtained from the second wave of the Ethiopia Socioeconomic Survey (ESS) 2013-2014 and the third wave of the Ethiopia Socioeconomic Survey (ESS) 20152016. The Ethiopian Socioeconomic Survey (ESS) is a collaborative long-term project between the Central Statistics Agency of Ethiopia (CSA) and the World Bank Living Standards Measurement Study-Integrated Surveys on Agriculture (LSMS-ISA) team to collect panel data. The project responds to the data needs of the country, given the dependence of a high percentage of households in agriculture activities in the country. The ESS collects information on household agricultural activities along with other information on the households like human capital, other economic activities, access to services and resources. The ability to follow the same households over time makes the ESS a new and powerful tool for studying and understanding the role of agriculture in household welfare over time as it allows analyses of how households add to their human and physical capital, how education affects earnings, and the role of government policies and programs on poverty, inter alia. The ESS is the first panel survey to be carried out by the CSA that links a multi-topic household questionnaire with detailed data on agriculture.

ESS uses a nationally representative sample of over 5,000 households living in rural and urban areas. The urban areas include both small and large towns. The sample is a two-stage probability sample. The first stage of sampling entailed selecting primary sampling units, which are a sample of the CSA enumeration areas (EAs). The second stage of sampling was the selection of households to be interviewed in each EA. A total of 433 EAs were selected based on probability proportional to size of the total EAs in each region out of which 290 were rural, 43 were small town EAs from ESS1, and 100 were EAs from major urban areas. In order to ensure sufficient sample size in the most populous regions (Amhara, Oromiya, SNNP, and Tigray) and Addis Ababa, quotas were set for the number of EAs in each region. The sample is not representative for each of the small regions including Afar, Benshangul Gumuz, Dire Dawa, Gambella, Harari, and Somalie regions. However, estimates can be produced for a combination of all smaller regions as one "other region" category.

During wave 3, 1255 households were re-interviewed yielding a response rate of 85 percent. Attrition in urban areas is $15 \%$ due to consent refusal and inability to trace the whereabouts of sample households.

Yield stands for the yield of maize per unit of land cropped measured in quintals per hectare.

LnYield stands for the natural logarithmic transformation of Yield.

HHAGE stands for the age of a household head in years.

HHSEX is a dummy variable indicating the sex of a household head where HHSEX $=1$ if the head is male and 0 if otherwise.

HHEDU is a dummy variable indicating whether a household head is literate where HHEDU $=1$ if the head is literate/able to read and write in any language / and 0 if otherwise.

HHRELIGION is a dummy variable indicating the main religion of a household head.

FAMILY SIZE stands for size of a household.

CREDIT is a dummy variable indicating household's access to credit where CREDIT $=1$ if anyone in the household has borrowed greater than 150 birr from someone outside the household or from an institution for business or farming purposes over the past 12 months and 0 if otherwise.

LANDHOLDING SIZE stands for size of the land holding of a household measured in meter squared.

OVERALLPLOTOWN is a dummy variable indicating household's plot ownership where OVERALLPLOTOWN $=1$ if the household has some plot under its ownership (acquired through inheritance or local leaders' grant) and 0 if otherwise.

AVERPLOTSLOPE stands for the average plot slope of a household' overall plot measured in percent.

OVERALLFERTILEPLOT is a dummy variable indicating household's overall plot soil quality where

OVERALLFERTILEPLOT $=1$ if the household has some plot with fair or good soil quality and 0 if otherwise.

DSTNEARMKT stands for distance to the nearest market from residence measured in kilometer.

DSTMAJROAD stands for distance to the nearest major road from residence measured in kilometer.

DSTNEARPOPCENTER stands for distance to the nearest population center with more than 20,000 people

from residence measured in kilometer.

OXEN stands for the total number of oxen owned by a household.

HHTLU stands for the total livestock units currently owned and kept by a household.

EXCONTACT is a dummy variable indicating whether a household had participated in the extension program where EXCONTACT $=1$ if the household had participated in the extension program and 0 if otherwise.

NONAGRIBUSIN is a dummy variable indicating whether a household owned a non-agriculture business or 
provided a non-agricultural service from home over the past 12 months where NONAGRIBUSIN $=1$ if the household has owned a non-agriculture business or provided a non-agricultural service from home over the past 12 months and 0 if otherwise.

COMIRRIGSCH is a dummy variable indicating presence of an irrigation scheme in the community in which a household reside where COMIRRIGSCH $=1$ if the community in which a household reside has an irrigation scheme and 0 if otherwise.

AMTOFRAIN is a dummy variable indicating the amount of rain received in the last season.

\section{Results and Discussions}

\subsection{Descriptive Statistics}

Various variables that were included in the propensity score matching model that describe the major observed characteristics of the sample respondents are presented in table 1.

\subsection{Propensity Scores Estimation using Probit Model}

Propensity scores for late adopters and non-adopters of fertilizer were estimated using a probit model to compare the treatment group with the control group. In this regard, only those variables that significantly affect probability of fertilizer adoption were used in estimating the propensity scores. The check for 'overlap condition' across the treatment and control groups was done and the result as indicated on figure 1 showed that the overlap condition is satisfied as there is substantial overlap in the distribution of the propensity scores of both late adopters and nonadopters. Each observation's propensity scores are calculated using a probit model. The propensity score for late adopters ranges between 0.116198 and 0.8927932 while it ranges between 0.0035742 and 0.83571 for nonadopters. And the region of common support for the distribution of estimated propensity scores of late adopters and non-adopters ranges between 0.116198 and 0.89279323 . When matching techniques are employed, observations whose propensity score lies outside this range were discarded.

\subsection{Assessing Matching Quality}

Ensuring good balance between treated and control group is the most important step in using any propensity score method. The before and after matching covariate balancing tests presented on table 2 suggested that the proposed specification of the propensity score is fairly successful in balancing the distribution of covariates between the two groups as indicated by decreasing pseudo $\mathrm{R}^{2}$, decreasing mean standardized bias and satisfied interval value of Rubin's R (ratio of treated to (matched) non-treated variances of the propensity score index) after matching.

\subsection{Average Treatment Effect on the Treated}

The ATT, calculated with the differences in differences (DD) estimator and different matching algorithms (nearest neighbor matching one and five $(\mathrm{NN}=1$ and $\mathrm{NN}=5)$ as well as Epanechnikov kernel matching with two band widths $(\mathrm{BW}=0.03$ and $\mathrm{BW}=0.06)$, i.e.), are shown in table 3. Adoption of fertilizer has some positive effects. During the period of investigation this technology increased yield growth of maize by $29-33 \%$. These results are quite different from the simple comparison of yield growth in table 1, confirming that there is significant negative selection bias. That means, farmers with lower than average yield growth are more likely to adopt fertilizer. Hence, a simple comparison between late adopters and non-adopters underestimates the technology's treatment effect. This selection bias is controlled for by the PSM and DD methodology. Moreover, most of the estimates in table 3 are significant, underlining the robustness of the results.

\section{Conclusion and Recommendation}

This study is undertaken to identify the impact of adoption of fertilizer on maize yield growth in Ethiopia. Unlike most previous impact studies of different improved agricultural technologies and practices, it used panel data covering two time periods. This allowed propensity score matching (PSM) to be combined with a difference-indifferences (DD) estimator to better match control and project units on preprogram observable characteristics and to control for certain types of unobserved variables which can be assumed to remain fixed over a shorter time series. The study also employed and compared various matching algorithms to ensure robustness of the impact estimates. The estimation results show that adoption of fertilizer had positive and significant impact on maize yield growth at national level. Therefore, this study recommends to widely scale-up fertilizer to all maize producing farm households, and this should be accompanied by increasing availability of affordable fertilizer for the smallholder farmers to enhance their livelihood which obviously calls for the well-coordinated, effective as well as efficient effort of all of the relevant stakeholders of the agricultural sector of the country. 


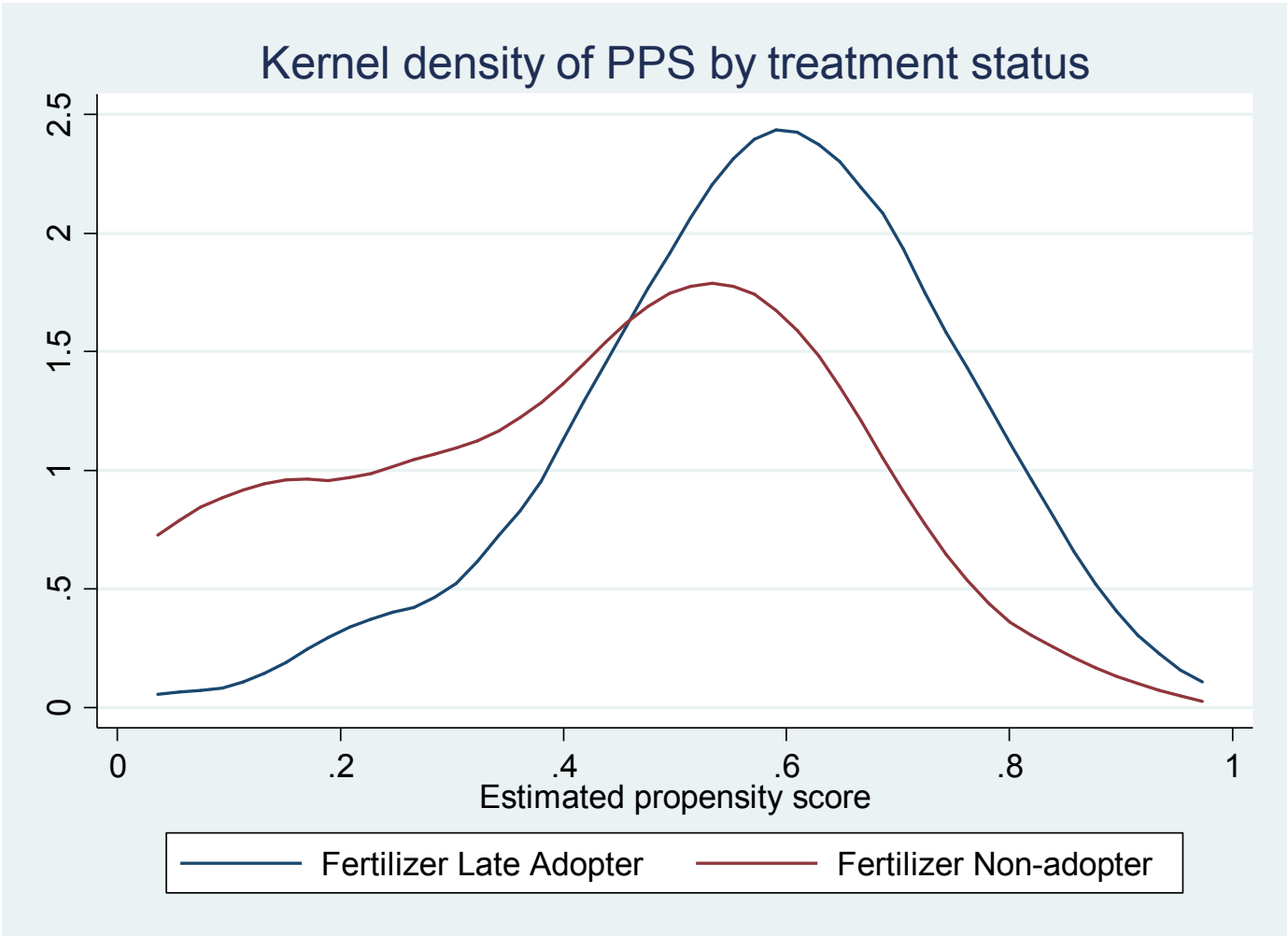

Figure 1: Distribution of propensity scores of late adopters and non-adopters

Table 1: Descriptive statistics of important variables used in the probit model-Propensity score matching (2013-2014)

\begin{tabular}{|c|c|c|c|c|c|}
\hline Variables & Unit & $\begin{array}{l}\text { Late Adopters } \\
\text { of Fertilizer } \\
\text { Mean(se) }\end{array}$ & $\begin{array}{c}\text { Non-Adopters } \\
\text { of Fertilizer } \\
\text { Mean(se) }\end{array}$ & $\begin{array}{l}\text { Aggregate } \\
\text { Mean(se) }\end{array}$ & t-stat. \\
\hline \multicolumn{6}{|l|}{ Outcome variable } \\
\hline Yield & $\#$ & $285.68(233.17)$ & $47.67(18.61)$ & $141.08(92.21)$ & -1.26 \\
\hline LnYield & $\%$ & $2.63(0.1290)$ & $2.76(0.0851)$ & $2.71(0.0723)$ & 0.895 \\
\hline \multicolumn{6}{|l|}{$\begin{array}{l}\text { Variables that affect } \\
\text { probability of adoption }\end{array}$} \\
\hline HHAGE & $\#$ & $42.74(1.223)$ & $45.02(1.148)$ & $44.13(0.848)$ & $1.31 *$ \\
\hline HHSEX (Male=1) & $1=$ Yes & $1.15(0.034)$ & $1.16(0.028)$ & $1.157(0.0215)$ & 0.186 \\
\hline $\begin{array}{l}\text { HHEDU } \\
\text { write=1) }\end{array} \quad$ Read $\quad \&$ & $1=$ yes & $1.55(0.047)$ & $1.69(0.035)$ & $1.64(0.029)$ & $2.31 * *$ \\
\hline HHRELIGION & $\begin{array}{l}1=\text { Or- } \\
\text { thodox }\end{array}$ & $0.375(0.046)$ & $0.286(0.034)$ & $0.321(0.028)$ & $-1.58^{*}$ \\
\hline HHRELIGION & $\begin{array}{l}1=\text { Pro- } \\
\text { testant }\end{array}$ & $0.205(0.038)$ & $0.234(0.032)$ & $0.223(0.025)$ & 0.573 \\
\hline HHRELIGION & $\begin{array}{c}\text { 1= Mus- } \\
\text { lem }\end{array}$ & $0.384(0.046)$ & $0.423(0.037)$ & $0.408(0.029)$ & 0.653 \\
\hline FAMILY SIZE & $\#$ & $5.65(0.222)$ & $5.59(0.175)$ & $5.62(0.137)$ & -0.204 \\
\hline CREDIT & $1=$ yes & $0.143(0.033)$ & $0.126(0.025)$ & $0.132(0.020)$ & -0.417 \\
\hline LANDHOLDING_SIZE & Sq.m & $17418.5(1715.8)$ & $18499.3(1326.4)$ & $18037.9(1048.9)$ & 0.48 \\
\hline OVERALLPLOT-OWN & $1=$ yes & $0.955(0.0196)$ & $0.903(0.0225)$ & $0.923(0.0157)$ & $-1.633 *$ \\
\hline AVERPLOTSLO-PE & $\%$ & $14.77(0.898)$ & $12.50(0.821)$ & $13.39(0.613)$ & $-1.811 * *$ \\
\hline $\begin{array}{l}\text { OVERALLFER- } \\
\text { TILEPLOT }\end{array}$ & $1=$ yes & $0.86(0.033)$ & $0.839(0.028)$ & $0.849(0.0212)$ & -0.5913 \\
\hline DSTNEARMKT & $\mathrm{km}$ & $80.06(4.63)$ & $92.25(5.16)$ & $87.49(3.64)$ & $1.64 *$ \\
\hline DSTMAJROAD & $\mathrm{km}$ & $17.45(1.57)$ & $16.63(1.42)$ & $16.95(1.06)$ & -0.374 \\
\hline DSTNEARPOP- & $\mathrm{km}$ & $56.03(3.46)$ & $47.59(2.14)$ & $50.88(1.89)$ & $-2.196 * *$ \\
\hline
\end{tabular}




\begin{tabular}{|l|c|c|c|c|c|}
\hline \multicolumn{1}{|c|}{ Variables } & Unit & $\begin{array}{c}\text { Late Adopters } \\
\text { of Fertilizer } \\
\text { Mean(se) }\end{array}$ & $\begin{array}{c}\text { Non-Adopters } \\
\text { of Fertilizer } \\
\text { Mean(se) }\end{array}$ & $\begin{array}{c}\text { Aggregate } \\
\text { Mean(se) }\end{array}$ & t-stat. \\
\hline CENTER & & & & & \\
\hline OXEN & $\#$ & $1.03(0.118)$ & $0.977(0.085)$ & $0.9965(0.069)$ & -0.3515 \\
\hline HHTLU & $\#$ & $2.69(0.221)$ & $3.41(0.265)$ & $3.117(0.182)$ & $1.927^{* *}$ \\
\hline EXCONTACT & $1=$ yes & $0.286(0.043)$ & $0.217(0.031)$ & $0.244(0.025)$ & $-1.319^{*}$ \\
\hline NONAGRIBUSIN & $1=$ yes & $1.93(0.024)$ & $1.87(0.025)$ & $1.895(0.018)$ & $-1.467^{*}$ \\
\hline COMIRRIGSCH & $1=$ yes & $1.24(0.041)$ & $1.52(0.038)$ & $1.41(0.029)$ & $4.91 * * *$ \\
\hline AMTOFRAIN & $\begin{array}{c}1=\text { Too } \\
\text { Much }\end{array}$ & $0.286(0.043)$ & $0.28(0.034)$ & $0.282(0.027)$ & -0.105 \\
\hline AMTOFRAIN & $\begin{array}{c}1=\text { Right } \\
\text { Amount }\end{array}$ & $0.688(0.044)$ & $0.514(0.038)$ & $0.582(0.029)$ & $2.935^{* * *}$ \\
\hline AMTOFRAIN & $\begin{array}{c}1=\text { Too } \\
\text { little }\end{array}$ & $0.027(0.015)$ & $0.2(0.030)$ & $0.132(0.02)$ & $4.346^{* * *}$ \\
\hline
\end{tabular}

***, **, * indicate significance at 1 percent, 5 percent and 10 percent level respectively.

Source: Own computation, 2020

Table 2: Propensity score matching quality test

\begin{tabular}{|l|c|c|c|c|c|c|c|}
\hline \multicolumn{1}{|c|}{ Sample } & Ps R2 & LR chi2 & p>chi2 & Meanbias & Medbias & R & \%Var \\
\hline Unmatched & 0.166 & 57.09 & 0.000 & 27.8 & 21.0 & $0.41^{*}$ & 50 \\
\hline Matched & 0.049 & 12.94 & 0.297 & 10.8 & 8.8 & 1.03 & 25 \\
\hline
\end{tabular}

$*$ if $\mathrm{B}>25 \%, \mathrm{R}$ outside $[0.5 ; 2]$

Table 3: Average treatment effect on the treated (ATT) of fertilizer (2013-2014 and 2015-2016)

\begin{tabular}{|c|l|c|}
\hline \multirow{3}{*}{ Outcome Variable } & \multicolumn{1}{|c|}{ Matching Algorithm } & ATT (Std. Err.) \\
\hline \multirow{3}{*}{ LnYield } & Nearest Neighbor (NN=1) & $0.333(0.267)$ \\
\cline { 2 - 3 } & Nearest Neighbor (NN=5) & $0.289 *(0.220)$ \\
\cline { 2 - 3 } & Kernel $(\mathrm{BW}=0.03)$ & $0.325^{*}(0.214)$ \\
\cline { 2 - 3 } & Kernel $(\mathrm{BW}=0.06)$ & $0.287 *(0.211)$ \\
\hline
\end{tabular}

* indicate significance at $10 \%$ level and bootstrapped standard errors are based on 100 replications.

Source: Own computation, 2020

\section{REFERENCES}

Abate T. , Shiferaw B., Menkir A., Wegary D. , Kebede Y., Tesfaye K., Kassie M., Bogale G., Tadesse B. and Keno T. (2015). Factors That Transformed Maize Productivity in Ethiopia. Food Sec. (2015) 7:965-981.

Abegaz G. (2011). Cereal Productivity in Ethiopia: An Analysis Based on ERHS Data. Ethiopian Journal of Economics, Volume XX No. 2, October 2011.

Ayele G., Bekele M. and Zekeria S. (2006). Productivity and Efficiency of Agricultural Extension Package in Ethiopia. Ethiopian Development Research Institute (EDRI), Research Report 5.

Bor O. and Bayaner A. (2009). How Responsive is the Crop Yield to producer prices? A panel data approach for the case of Turkey. NEW MEDIT N. 4/2009.

Central Statistics Agency of Ethiopia (CSA). Ethiopia Socioeconomic Survey 2013-2014, Ref. ETH_2013_ESS_v02_M. Dataset from https://microdata.worldbank.org/index.php/catalog/2247/download/41577 on 9/17/2019.

Central Statistical Agency of Ethiopia (CSA). Ethiopia Socioeconomic Survey, Wave 3 (ESS3) 2015-2016. Public Use Dataset. Ref: ETH 2015 ESS v02 M. Downloaded from https://microdata.worldbank.org/index.php/catalog/2783/download/41756 on 9/17/2019.

Crown W.H. Propensity-Score Matching in Economic Analyses: Comparison with Regression Models, Instrumental Variables, Residual Inclusion, Differences-in-Differences, and Decomposition Methods.

CSA. 2015. Major results of the 2007 GDP estimates. Central Statistical Agency (CSA), Addis Ababa, Ethiopia.

Daniel F. (2018). Impact of Improved Wheat Varieties Adoption on Productivity: Ethiopia. LAP LAMBERT Academic Publishing, Beau Bassin. ISBN: 978-613-7-42438-4.

Daniel F. and Belay B. (2018). Impact of Improved Wheat Varieties \& Information's Adoption on Productivity in Ethiopia. GRIN Publishing, Munich. ISBN: 9783668808096.

Elias A.,Nohmi M., Yasunobu K. \& Ishida A. (2013). Effect of Agricultural Extension Program on Smallholders ${ }^{\text {ee }}$ Farm Productivity: Evidence from Three Peasant Associations in the Highlands of Ethiopia. Journal of 
Agricultural Science, Vol. 5, No. 8, 2013.

Endale K. (2011). Fertilizer Consumption and Agricultural Productivity in Ethiopia. Ethiopian Development Research Institute (EDRI), Working Paper 003.

GebreEyesus A. (2015). A Study on Human Resource Management, Staff Turnover and Incentives in the National Agricultural Research System (NARS). Ethiopian Development Research Institute (EDRI), Research Report 27.

Gebre-Selassie A. and Bekele T. A Review of Ethiopian Agriculture: Roles, Policy and Small-scale Farming Systems. Global Growing Casebook.

Gebru A. (2006). The Determinants of Modern Agricultural Inputs Adoption and Their Productivity in Ethiopia (The Case of Amhara and Tigray Regions). A Thesis Submitted to the School of Graduate Studies of Addis Ababa University in Partial Fulfillment of the Requirements for the Degree of Master of Science in Economics (Economic Policy Analysis), July, 2006.

Gertler P.J., Martinez S., Premand P., Rawlings L.B. and Vermeersch C.M. J. (2011). Impact Evaluation in Practice. The International Bank for Reconstruction and Development /The World Bank.

González V., Ibarrarán P., Maffioli A. and Rozo S. (2009). The Impact of Technology Adoption on Agricultural Productivity: The Case of the Dominican Republic. Inter-American Development Bank. Office of Evaluation and Oversight Working Paper: OVE/WP05/09. September, 2009.

Haregewoin T., Belay B., Bezabeh E., Kelemu K., Hailu D. and Daniel F. (2018). Impact of Improved Wheat Variety on Productivity in Oromia Regional State, Ethiopia. Greener Journal of Agricultural Sciences, Vol. 8(4), pp. 074 - 081, April, 2018.

Jaleta, M., Kassie, M. and Marenya, P. (2015), "Impact of Improved Maize Variety Adoption on Household Food Security in Ethiopia: An Endogenous Switching Regression Approach", International Conference of Agricultural Economists.

Kelemu K. (2017). Determinants of Farmers Access to Information about Improved Wheat Varieties: Case of Farmers in Major Wheat Growing Regions of Ethiopia. International Journal of Research in Agricultural Sciences, Volume 4, Issue 1, ISSN (Online): 2348 - 3997.

Khandker S.R., Koolwal G.B. and Samad H.A. (2010). Handbook on Impact Evaluation-Quantitative Methods and Practices. The International Bank for Reconstruction and Development /The World Bank.

Matsumoto T. and Yamano T. (2010). The Impacts of Fertilizer Credit on Crop Production and Income in Ethiopia. National Graduate Institute for Policy Studies (GRIPS) Policy Research Center Discussion Paper 10-23, GRIPS, Tokyo.

MoFED. (2003). Rural Development Policy and Strategies. Economic Policy and Planning, Ministry of Finance and Economic Development, Addis Ababa.

Olmos A. (2015). Propensity Scores: A Practical Introduction Using R. Journal of Multi-Disciplinary Evaluation, Vol. 11, Issue 25, 2015.

Smith J. (2004). Evaluating Local Economic Development Policies: Theory and Practice.

Taffesse A., Dorosh P. and Asrat S. (2012). Crop Production in Ethiopia: Regional Patterns and Trends. Summary of ESSP II Working Paper 16, "Crop Production in Ethiopia: Regional Patterns and Trends". ETHIOPIA STRATEGY SUPPORT PROGRAM (ESSP II) Research Note 11.

Tsusaka T. and Otsuka K. (2013). The Changes in the Effects of Temperature and Rainfall on Cereal Crop Yields in Sub-Saharan Africa: A Country Level Panel Data Study, 1989 to 2004. Environmental Economics, Volume 4, Issue 2, 2013.

White H., Sinha S. and Flanagan A. A Review of the State of Impact Evaluation. Independent Evaluation Group, World Bank. 